\title{
A Method for the Determination of Guanidoacetic Acid and Arginine in Biological Fluids ${ }^{1,2}$
}

\author{
Chung Wu \\ From the Department of Internal Medicine, The University of \\ Michigan Medical School, Ann Arbor, Michigan
}

Received May 25, 1959

\section{INTRODUCTION}

The determination of guanidoacetic acid in biological fluids has assumed greater importance since the demonstration that this compound is an intermediate in the biosynthesis of creatine (1-3). In the reported studies of creatine metabolism (4-6), guanidoacetic acid has been determined exclusively with the Sakaguchi reaction, which is given by monosubstituted guanidines. It has been shown recently that arginine and guanidoacetic acid are the only two monosubstituted guanidines present in significant quantities in man (7) and probably in higher animals. Hence the reliable determination of guaniduacetic acid or arginine by the Sakaguchi reaction requires the complete removal of the other reacting substance. In our investigation of creatine metabolism in tumor-bearing rats, which will be published elsewhere, we became aware of the inadequacy and inconvenience of the available methods for the estimation of guanidoacetic acid. An effort was therefore made to develop a reliable and quantitative assay procedure for the two Sakaguchi-positive compounds in biological materials. The results of such a study are the subject of this communication.

The present method is based on the observation that from a mixture of guanidoacetic acid and arginine the weakly cationic resin, Amberlite CG-50, adsorbs the arginine quantitatively. The guanidoacetic acid thus freed from arginine is separated from certain interfering substances by its adsorption on the strongly cationic resin, Nalcite HCR-8. Elution of the two resins gives solutions of arginine and of guanidoacetic acid which can be determined separately and directly by the Sakaguchi reaction.

1 A part of this work was presented at the Division of Biological Chemistry, the 135th National Meeting of the American Chemical Society, Boston, Mass., April 5-10, 1959.

2 This investigation was supported in part by a research grant USPHS C-1719 from the National Cancer Institute, National Institutes of IIealth, U. S. Public Health Service. 


\section{Materials and Methods}

\section{Apparatus and Reagents for Chromatography}

1. Amberlite CG-50, passing 200 mesh (Rohm and Haas Company). The resin is supplied in the $\mathrm{H}$ form and is converted to the $\mathrm{Na}$ form by treating it with $1 \mathrm{~N} \mathrm{NaOH}$. The resin is subsequently washed with distilled water to remove excess alkali until the $\mathrm{pH}$ of the washings is about 10 .

2. Nalcite HCR-8, 200-400 mesh (National Aluminate Corporation). Used without further treatment.

3. Sodium acetate solution, $0.5 \mathrm{M}$.

4. Fritted-disk funnels, microfilter tube type with coarse porosity (Corning Glass Works), or, plain chromatographic tubes $(75 \times 10 \mathrm{~mm}$.) with fritted disk and buret type delivery tip below the stopcock.

\section{Reagents for Sakaguchi Reaction}

1. Alkaline thymine- $\alpha$-naphthol solution ( 7 ).

2. Sodium hypochlorite solution. Prepared by diluting Chlorox 1:15 with distilled water.

3. Sodium thiosulfate solution, $5 \%$ solution of $\mathrm{Na}_{2} \mathrm{~S}_{2} \mathrm{O}_{3} \cdot 5 \mathrm{H}_{2} \mathrm{O}$.

4. Standard solutions of guanidoacetic acid and arginine (Nutrilivnal Biochemicals Corporation), 0.01-0.2 $\mu \mathrm{mole} / 4 \mathrm{ml}$.

\section{Procedure}

Samples to be determined may be prepared as follows:

(a) Urine. Twenty-four-hour samples may be diluted to a certain arbitrary volume such as $1500 \mathrm{ml}$. An aliquot of this, usually 1.0-2.0 ml, is taken for chromatography. This measure is desirable to nearly equalize the concentration of nonspecific substances which might later interfere with the color reaction.

(b) Plasma. Blood plasma may be used without deproteinization. However, it was found more convenient to use the protein-free filtrate. One milliliter of plasma is deproteinized with $2 \mathrm{ml}$. of $6 \%$ trichloroacetic acid. Two milliliters of the supernatant are used for chromatography.

(c) Kidney Extract. This is prepared by homogenizing kidney tissue in distilled water with a Potter-Elvehjem homogenizer and centrifuging to remove tissue debris. The supernatant solution may be chromatographed without deproteinization. However, for ease in chromatography, the homogenate may be deproteinized by either heating (8) or treating with $4 \%$ trichloroacetic acid, final concentration. An aliquot of the protein free supernatant equivalent to $10 \mathrm{mg}$. tissue (dry weight) may be chromatographed.

Chromatography. Into one microfilter tube type funnel with fritted disk is introduced Amberlite CG-50, Na form, to a height of about $1 \mathrm{~cm}$, , and into another funnel Nalcite HCR-8 is added to a similar height. The Amberlite funnel is placed straight above the Nalcite funnel with the tip of the former slightly inside the top opening of the latter so that the effluent from the upper funnel will run directly into the lower funnel (Fig. 1). The funnels may be secured in position with clamps fastened to an iron stand. However, when a large number of analyses is attempted, two rows of properly placed clips mounted on a board capable of holding a dozen funnels in each row are recommended.

Samples to be chromatographed may contain $0.05-0.2 \mu$ mole each of arginine and of guanidoacetic acid. Samples containing more than $0.2 \mu$ mole could be used, but 


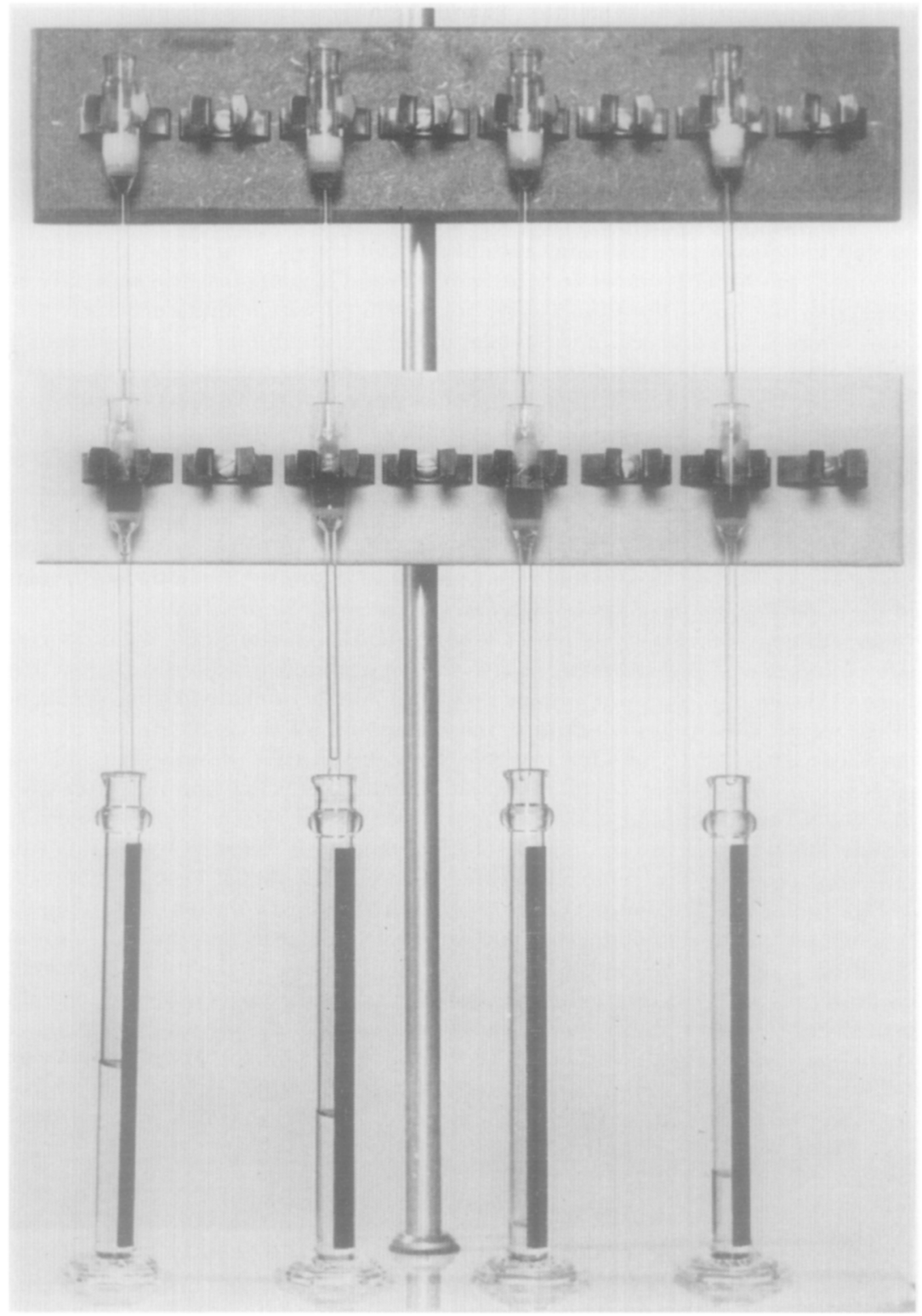

FIG. 1. Assembly for chromatographic separation of guanidoacetic acid from arginine with Amberlite CG-50 and Nalcite HCR-8.

in this case volumes of eluates taken for color development should be proportionally less than $4 \mathrm{ml}$. The sample is added dropwise into the Amberlite funnel and followed by distilled water. About $10 \mathrm{ml}$. effluent from the Nalcite funnel is collected and discarded. Then one of the funnels is removed and placed beside the other. To each 
funnel $0.5 M$ sodium acetate solution is added slowly until $10 \mathrm{ml}$. eluate from each has been collected. The eluate containing arginine or guanidoacetic acid is used for color determination. Each of the washing and eluting steps takes about 20-30 min. Therefore, the whole procedure of chromatography should take no more than $1 \mathrm{hr}$. A dozen samples at a time can be chromatographed easily. When nondeproteinized plasma or kidney extract is used, a thin layer of substances, presumably proteins, occasionally forms on top of the resin, which slows down the rate of flow appreciably. If this happens, the surface of the resin may be gently disturbed to break up the layer and thereby restore the usual rate of flow. Of course, if arginine alone is to be determined, the Nalcite funnel may be omitted; and if guanidoacetic acid only is to be analyzed, the Amberlite funnel need not be eluted with sodium acetate.

Since there is no stopcock in the funnel used, the rate of flow is controlled by the porosity of the disk, the size of the resin particles, and the rate at which the solution is introduced into the funnel. If each of the washing and eluting processes is carried out in no less than $20 \mathrm{~min}$., satisfactory results will be obtained. Since the height of the resin in each funnel is short, it does not create sufficient pressure to draw air into the resin when liquid level is allowed to fall below the surface of the resin. However, the setup does require constant attention during chromatography since only a small volume of liquid should be introduced at a time. It would be easier for the operator to use a longer column (approximately $75 \mathrm{~mm}$.) of a similar diameter and regulate the rate of outflow by means of a stopcock with a capillary delivery tip.

Color Development. Two aliquots of $4 \mathrm{ml}$. or less from the $10-\mathrm{ml}$. sodium acetate eluate of arginine or guanidoacetic acid are used for duplicate determinations. If the volume of the eluate taken is less than $4 \mathrm{ml}$. it should be brought to this volume with distilled water. Test tubes containing the eluate and all the reagents are placed in an ice water bath at $2^{\circ} \mathrm{C}$. for a few minutes. To each test tube are added the following reagents: $1 \mathrm{ml}$. of alkaline thymine- $\alpha$-naphthol solution, a few minutes later $0.5 \mathrm{ml}$. of the $\mathrm{NaOCl}$ solution, and another $3 \mathrm{~min}$. later $0.5 \mathrm{ml}$. of the sodium thiosulfate solution. The addition of the $\mathrm{NaOCl}$ solution should be followed by an immediate and thorough mixing. The color is measured in round cuvettes of $19 \times 105 \mathrm{~mm}$. with a Coleman Junior spectrophotometer at $500 \mathrm{~m} \mu$. A standard solution containing $0.01-$ $0.06 \mu$ mole arginine or guanidoacetic acid in $4 \mathrm{ml}$. volume is determined simultaneously. Beer's law holds well in this range of concentrations. In the presence of sodium thiosulfate, the molar extinction coefficients for arginine and guanidoacetic acid are practically the same with a value of 15,800 . Although the color which develops appears to be reasonably stable at $2^{\circ} \mathrm{C}$. or thereabouts, the blank reading shows a steady increase in the first $15 \mathrm{~min}$. following the addition of $\mathrm{NaOCl}$. Hence, it is advisable to measure the color $15 \mathrm{~min}$. after the addition of $\mathrm{NaOCl}$, at which time corrections for the blank readings are quite constant.

\section{Results}

It was observed that under certain conditions the weakly cationic resin, Amberlite CG-50, could adsorb quantitatively arginine but not guanidoacetic acid from a solution containing both substances, thereby serving as a means to separate these two compounds. In Table I comparison is made of the effectiveness of the two forms of Amberlite CG-50 in adsorbing guanidoacetic acid and arginine. To give a clean-cut separation of the two compounds, the resin should adsorb all arginine but no guanidoacetic acid. A diluted human urine sample containing added arginine or added guanido- 


\section{TABLE I}

Adsorption of Guanidoacetic Acid and of Arginine from II uman Urine by the $H$ and Na Forms of Amberlite CG-50

One milliliter of diluted urine containing added guanidoacetic acid or added arginine in quantities listed in the third and fourth columns was chromatographed as described in the Procedure.

\begin{tabular}{|c|c|c|c|c|}
\hline Form of resin & $\mathrm{pH}$ of urine & $\begin{array}{l}\text { Guanidoacetic acid } \\
\text { added }\end{array}$ & Arginine added & $\begin{array}{l}\text { Per cent of added } \\
\text { compound adsorbed }\end{array}$ \\
\hline & & umole & $\mu$ moles & \\
\hline \multirow[t]{6}{*}{$\mathrm{H}$} & 4.0 & 0.15 & 0 & 16.0 \\
\hline & & 0 & 2.25 & 78.0 \\
\hline & 7.5 & 0.15 & 0 & 5.4 \\
\hline & & 0 & 2.25 & 86.0 \\
\hline & 10.4 & 0.15 & 0 & 12.0 \\
\hline & & 0 & 2.25 & 92.4 \\
\hline \multirow[t]{6}{*}{$\mathrm{Na}$} & 4.0 & 0.15 & 0 & 0.0 \\
\hline & & 0 & 2.25 & 99.9 \\
\hline & 7.5 & 0.15 & 0 & 0.0 \\
\hline & & 0 & 2.25 & 99.6 \\
\hline & 10.4 & 0.15 & 0 & 0.0 \\
\hline & & 0 & 2.25 & 100.0 \\
\hline
\end{tabular}

acetic acid was run through each form of the resin in a fritted-disk funnel followed by distilled water until $10 \mathrm{ml}$. of the effluent had been collected. The added compound in the effluent was determined. The difference between the amount added and the amount present in the effluent indicated the amount adsorbed on the resin. In order to study the effect of $\mathrm{pH}$ upon the adsorption, the urine sample was adjusted to different $\mathrm{pH}$ values. The results summarized in this table show that the Na form of Amberlite CG-50 was far superior to its $\mathrm{H}$ form in separating arginine from guanidoacetic acid in a wide range of $\mathrm{pH}$ valucs. Thus, in the efflucnts from the resin in the $\mathrm{Na}$ form, all added guanidoacetic acid could be quantitatively recovered and none of the added arginine could be detected. On the other hand, the effluents from the resin in the $\mathrm{H}$ form contained an appreciable percentage of the added arginine, although the recovery of guanidoacetic acid was progressively increased at the higher $\mathrm{pH}$ values.

Since the resin in the Na form did not adsorb guanidoacetic acid at all, it should be possible to recover all of it in the washings. This was not always true. It was noted that the recovery of guanidoacetic acid added to a certain urine sample varied with the volume of the urine chromatographed. The larger the volume of urine used the lower was the recovery of guanidoacetic acid. For example, the recovery values of added guanidoacetic acid were 48,69 , and $98 \%$ when the amounts of a given urine sample run through Amberlite CG-50, Na form, were 3, 2, and $1 \mathrm{ml}$., respectively. The observa- 
tion clearly indicated interference by substances in urine. To remove the interfering substances, it was found necessary to use the strongly cationic resin, Nalcite HCR-8, to adsorb guanidoacetic acid from the arginine-free solution which had passed through Amberlite CG-50. The interfering substances, being apparently not adsorbed by either of the resins, were contained in the solution emerging from Nalcite HCR-8. Addition of guanidoacetic acid to this solution could be recovered only very poorly.

Recovery of both guanidoacetic acid and argininc added to a urine sample in a wide range of ratios was next investigated. Arginine was eluted from the Amberlite funnel and guanidoacetic acid from the Nalcite funnel as described under Procedure. The results in Table II indicate that a range of recovery from 96.7 to $104.0 \%$ was obtained with ratios of guanidoacetic acid to arginine being from 1:50 to 50:1. This range of ratios presumably covers all combinations of these two compounds that might occur in biological systems. The recovery data with rat plasma were likewise satisfactory. One application of this method may be for the assay of transamidinase activity, in which small quantities of guanidoacetic acid synthesized are determined in the presence of substrate amounts of arginine. The results with kidney extract have demonstrated the suitability of this method for such an assay. Guanidoacetic acid was successfully determined in the presence of at least 100 -fold concentration of arginine. Furthermore, it may be pointed out that from $0.037 \mu$ mole to at least $9.5 \mu$ moles of either

\section{TABLE II}

Recovery of Added Guanidoacetic Acid and of Added Arginine in Urine, Plasma and Kidney Extract

Urine, plasma, and kidney extract containing the added compounds in quantities listed in the first two columns were chromatographed as described in the Procedure. Aliquots of the $10-\mathrm{ml}$. eluates were used for color determinations.

\begin{tabular}{|c|c|c|c|}
\hline \multicolumn{2}{|c|}{ Micromoles added } & \multicolumn{2}{|c|}{ Per cent recovered } \\
\hline Guanidoacetic acid & Arginine & Guanidoacetic acid & Arginine \\
\hline \multicolumn{4}{|l|}{ Human urine: } \\
\hline 0.037 & 1.85 & 98.7 & 102.1 \\
\hline 0.113 & 1.13 & 103.9 & 102.6 \\
\hline 0.185 & 0.370 & 103.7 & 102.5 \\
\hline 0.300 & 0.150 & 96.7 & 101.6 \\
\hline 1.50 & 0.150 & 104.0 & 103.2 \\
\hline 1.85 & 0.037 & 97.9 & 98.7 \\
\hline \multicolumn{4}{|l|}{ Rat plasma: } \\
\hline 1.25 & 0.125 & 104.0 & 102.0 \\
\hline 0.250 & 1.00 & 101.0 & 96.0 \\
\hline \multicolumn{4}{|c|}{ Rat kidney extract: } \\
\hline 0.095 & 9.50 & 100.0 & 102.9 \\
\hline
\end{tabular}


guanidoacetic acid or arginine or both could be quantitatively determined with the present chromatographic procedure.

Certain substances interfering with the Sakaguchi reaction are removed during chromatography, as shown by the very poor recovery of guanidoacetic acid when added to the washings emerging from the Nalcite in the experiment with urine. However, certain sulfhydryl compounds, such as glutathione and cysteine, and guanidine derivatives, such as creatine and creatinine, cannot be so removed. When present in appreciable quantities, these compounds serve as inhibitors in the Sakaguchi reaction. Together with arginine, creatinine is adsorbed by Amberlite CG-50 and is eluted with sodium acetate. Therefore, interference by creatinine, if any, is limited to arginine only. On the other hand, creatine, glutathione, and cysteine behave similarly to guanidoacetic acid during chromatography, and their interference may be expected only with the guanidoacetic acid determination. The amounts of creatinine, glutathione, and cysteine needed to cause a $50 \%$ reduction of the color formation by $0.05 \mu$ mole arginine or guanidoacetic acid per color tube were estimated to be 13,3 , and $5 \mu$ moles, respectively. While these three compounds interfere by reducing the color formed, they do not give any color with the Sakaguchi reagents. This is not true, however, with creatine. This compound produces with the reagents a greenish yellow color, when the amount exceeds $1 \mu$ mole per color tube. Certainly, there are other compounds which when present in high concentrations will interfere with the color reaction, but these four compounds either appear to interfere at somewhat low concentrations, or occur in fairly large quantities in certain biological fluids, such as creatinine in urine. When a sample is to be analyzed for guanidoacetic acid or arginine, it is advisable to have a rough estimate of the interfering substances present. When this is done, it is generally possible to use an amount of the sample for the assay without any or with minimal inhibition.

The values for guanidoacetic acid and arginine in normal human and rat plasma and urine as determined by the present method are given in Table III.

\section{Discussion}

The determination of guanidoacetic acid in biological fluids by the Sakaguchi reaction necessitates the removal of arginine. Three methods have been used to remove arginine, namely, $(a)$ column chromatography $(8,9),(b)$ arginase $(10)$, and $(c) \mathrm{ZnSO}_{4}-\mathrm{Ba}(\mathrm{OH})_{2}$ precipitation (7). Earlier work with column chromatography was laborious and to some extent unsatisfactory. One difficulty appears to be in the variable properties of Permutit used in different laboratories. For example, Dubnoff (11) reported that arginine adsorbed on Permutit could be eluted quantitatively with $3 \%$ 
TABLE III

Normal Values for Guanidoacetic Acid and Arginine in Plasma and Urine

\begin{tabular}{lcc}
\hline & Guanidoacetic acid & Arginine \\
\hline Plasma, $\mu$ moles $/ 100 \mathrm{ml} .:$ & & \\
Human, 8 men & 3.9 & 13.6 \\
Human, 5 women & $(3.5-4.3)^{a}$ & $(9.5-17.0)$ \\
Rat, 5 males & 3.9 & 11.7 \\
Urine, $\mu$ moles/day: & $(3.5-4.3)$ & $(9.0-16.0)$ \\
Human, 9 men & 5.3 & 18.2 \\
Rat, 16 males & $(4.5-6.0)$ & $(11.0-21.5)$ \\
& 546 & 81 \\
& $(360-800)$ & $(61-112)$ \\
\end{tabular}

${ }^{a}$ The values in the parentheses indicate the ranges.

$\mathrm{NaCl}$, while Albanese and Frankston (12) indicated the elution was very incomplete. The use of arginase has certain limitations. Within the convenience of an analytical procedure, large amounts of arginine could not be easily hydrolyzed (13). In addition, the large quantities of urea formed under these circumstances could cause some interference in subsequent color development. More recently, Van Pilsum et al. (7) introduced $\mathrm{ZnSO}_{4-}^{-}$ $\mathrm{Ba}(\mathrm{OH})_{2}$ precipitation to remove arginine. It was pointed out, however, that the precipitation could remove only limited amounts of arginine. Furthermore, it was noted that certain quantities of guanidoacetic acid were occasionally lost during the precipitation. In the arginase (10) and $\mathrm{ZnSO}_{4}-\mathrm{Ba}(\mathrm{OH})_{2}(7)$ methods and in the Albanese-Frankston modification (12) of the Permutit method (8), arginine can be determined by difference only. It is obvious that indirect measurements are not always satisfactory. In none of the methods mentioned above was any attempt made to remove certain substances which may interfere with the Sakaguchi reaction. These shortcomings have been overcome in the present method.

In Table IV, a summary is made of the values for guanidoacetic acid and arginine in normal human urine as determined by this and other methods. The values in the literature have been recalculated from milligrams/day to micromoles/day for comparison. It can be seen that the average values for arginine as determined by the three independent methods, namely, column chromatography, paper chromatography, and microbiological assay ranged from 34 to $115 \mu$ moles/day. The average value given by the present method is $81 \mu$ moles/day, which is within the limits obtained by the three methods mentioned above. On the other hand, the $\mathrm{ZnSO}_{4}-\mathrm{Ba}(\mathrm{OH})_{2}$ method gave $184 \mu$ moles/day, which is higher than any of these values. Further- 
TABLE IV

Comparison of Normal Values for Guanidoacetic Acid and Arginine in Human Urine by Different Methods

All values, unless otherwise indicated, are expressed as micromoles/day.

\begin{tabular}{|c|c|c|c|c|c|c|c|}
\hline \multirow{2}{*}{ Compound } & \multicolumn{4}{|c|}{ Sakaguchi reaction } & \multirow{2}{*}{$\begin{array}{c}\text { Column } \\
\text { chromato- } \\
\text { graphy } \\
(15)\end{array}$} & \multirow{2}{*}{$\begin{array}{c}\text { Paper } \\
\text { chromato- } \\
\text { graphy } \\
(16)\end{array}$} & \multirow{2}{*}{$\begin{array}{c}\text { Microbio- } \\
\text { logical } \\
\text { assay } \\
(17-20)\end{array}$} \\
\hline & $\begin{array}{l}\text { Present } \\
\text { methor }\end{array}$ & $\begin{array}{c}\mathrm{ZnSO}_{4-} \\
\mathrm{Ba}\left(\mathrm{OH}_{2}\right)_{2} \\
(7)^{a}\end{array}$ & $\underset{(12,14)}{\text { Permutit }}$ & $\underset{\text { (10) }}{\text { Arginase }}$ & & & \\
\hline Arginine & 81 & 184 & 500 & $<86^{b}$ & $<58$ & 75 & $34-115$ \\
\hline $\begin{array}{l}\text { Guanidoacetic } \\
\text { acid }\end{array}$ & 546 & 384 & 325 & 726 & & & \\
\hline
\end{tabular}

a The number in the parentheses refers to the literature cited.

${ }^{b}$ Micromoles per liter of urine.

more, the value of $500 \mu$ moles/day as determined with Permutit (12) appears to be much too high. Since no results for guanidoacetic acid determined by other independent methods are available, it is difficult to comment on the values obtained with other methods employing the Sakaguchi reaction with respect to that of the present method. However, it can be seen that the arginase method gave the highest value and the Permutit method (14) gave the lowest.

Although the present method utilizes the principle of chromatography, the chromatographic procedure has been greatly simplified. The method appears to be preferable for the determination of arginine and guanidoacetic acid for several reasons: (a) No elaborate chromatographic apparatus is needed, and the operation is simple and rapid; $(b)$ the method is versatile, in that it can be used to determine on a single sample either arginine or guanidoacetic acid or both; (c) each compound is determined independently and directly, and there is no estimation by difference; $(d)$ one compound can be determined in the presence of at least 100 -fold concentration of another; and $(e)$ certain substances interfering with the Sakaguchi color reaction have been removed.

\section{SUMMARY}

A method for the determination of either arginine or guanidoacetic acid or both in biological materials has been presented. The method is based on the chromatographic separation of arginine from guanidoacetic acid and the direct determination of each compound by the Sakaguchi reaction. The recovery of added compounds to urine, plasma, and kidney extracts ranges from 96.0 to $104.0 \%$. 


\section{REFERENCES}

1. Block, K., ANd Schoenheimer, R., J. Biol. Chem. 138, 167 (1941).

2. Borsook, H., And Dubnoff, J. W., J. Biol. Chem. 132, 559 (1940).

3. du Vigneaud, V., Cohn, M., Chandler, J. P., Schenck, J. R., And Simmonds, S., J. Biol. Chem. 140, 625 (1941).

4. Dinning, J. S., and Fitch, C. D., Proc. Soc. Exptl. Biol. Med. 97, 109 (1958).

5. Mangiantini, M. T., Arch. sci. biol. (Bologna) 41, 430 (1957).

6. Melville, R. S., ANd Hummel, J. P., J. Biol. Chem. 191, 383 (1951).

7. Van Pilsum, J. F., Martin, R. P., Kito, E., and IIess, J., J. Biol. Chem. 222, 225 (1956).

8. Dubnoff, J. W., And Borsook, H., J. Biol. Chem. 138, 381 (1941).

9. Sims, E. A. H., J. Biol. Chem. 168, 239 (1945).

10. Hoberman, H. D., J. Biol. Chem. 167, 721 (1947).

11. Dubnoff, J. W., J. Biol. Chem. 141, 711 (1941).

12. Albanese, A. A., and Frankston, J. E., J. Biol. Chem. 159, 185 (1945).

13. Van Pilsum, J. F., Berman, D. A., And Wolin, E. A., Proc. Soc. Exptl. Biol. Med. 95, 96 (1957).

14. Levedahl, B. H., ANd Samuels, L. T., J. Biol. Chem. 176, 327 (1948).

15. Stein, W. H., J. Biol. Chem. 201, 45 (1953).

16. Müriva, D., Z. physiol. Chem. 297, 61 (1954).

17. Borden, A. L., Brodie, E. C., Wallaraff, E. B., Holbrook, W. D., Hill, D. F., Stephens, C. A. L., Jr., Johnson, R. B., And Kemmerer, A. R., J. Clin. Invest. 31, 375 (1952).

18. Dunn, M. S., Camien, M. N., Shankman, S., and Block, H., Arch. Biochem. 13, 207 (1947).

19. Eckhardt, R. D., and Davidson, C. S., J. Clin. Invest. 27, 727 (1948).

20. Steele, B. F., Sauberlich, H. E., Reynolds, M. S., and Baumann, C. A., $J$. Nutrition 33, 209 (1947). 